\title{
MicroRNA-381 inhibits cell proliferation and invasion in endometrial carcinoma by targeting the IGF-1R
}

\author{
CHUNHUA TU, FEN WANG and JUNHUI WAN \\ Department of Obstetrics and Gynecology, The First Affiliated Hospital of Nanchang University, \\ Nanchang, Jiangxi 330006, P.R. China
}

Received May 22, 2017; Accepted September 12, 2017

DOI: $10.3892 / \mathrm{mmr} .2017 .8288$

\begin{abstract}
Endometrial carcinoma (EC) is the sixth most common type of malignant tumor occurring in females. MicroRNAs (miRNAs) serve as oncogenes or tumor suppressors in human cancer and play important roles in tumorigenesis, and tumor development by regulating various processes. Thus, further investigation into miRNAs involved in EC formation and progression may aid in developing effective therapeutic strategies for patients with this disease. miRNA-381 (miR-381) is aberrantly expressed in multiple types of human cancer. However, the expression pattern, biological roles and underlying mechanisms of miR-381 in EC are poorly understood. In the present study, the results showed that miR-381 was downregulated in EC tissues and cell lines. Decreased miR-381 expression correlated with the International Federation of Gynecology and Obstetrics stage, lymph nodes metastasis and myometrial invasion of EC. The ectopic expression of miR-381 significantly inhibited the proliferation and invasion of EC cells. Through a series of experiments, the insulin-like growth factor receptor 1 (IGF-1R) was identified as a novel direct target of miR-381 in EC. Furthermore, IGF-1R was highly expressed in EC tissues and inversely correlated with miR-381 levels. IGF-1R overexpression partially abrogated the tumor-suppressive effects of miR-381 on the proliferation and invasion of EC cells. miR-381 targeted IGF-1R to inactivate the protein kinase $\mathrm{B}$ (AKT) and extracellular signal-regulated kinase (ERK) signaling pathways in EC. These results suggest that miR-381 acts as a tumor suppressor in EC by directly targeting IGF-1R, and indirectly regulating the AKT and ERK signaling pathways. Thus, miR-381 should be investigated as
\end{abstract}

Correspondence to: Professor Junhui Wan, Department of Obstetrics and Gynecology, The First Affiliated Hospital of Nanchang University, 17 Yongwaizheng Road, Nanchang, Jiangxi 330006, P.R. China

E-mail:wan_junhui@sina.com

Key words: endometrial carcinoma, microRNA-381, proliferation, invasion, insulin-like growth factor receptor-1 a prognostic biomarker and novel therapeutic target for the treatment of patients with EC.

\section{Introduction}

Endometrial carcinoma (EC) is the sixth most common malignant tumor occurring in females. Approximately 319,600 new EC cases per year were estimated (1). Although Asian women have a lower risk of EC than those residing in the US and other western countries, the morbidity of EC in China has substantially increased (2). Several risk factors, including hypertension, obesity, diabetes, postmenopausal status, infertility, family history of EC and long-term use of oestrogen, contribute to EC formation and progression $(3,4)$. EC patients at the early stage generally have a good prognosis with a 5-year survival rate of up to $96 \%$ (5). By contrast, patients diagnosed at advanced stage are often associated with a worse outcome despite the recent advances in surgical treatments and chemoradiotherapy $(6,7)$. Therefore, determining the underlying molecular mechanisms of EC formation and development is urgently needed to create novel therapeutic approaches for EC and to increase prognosis for patients with this disease.

MicroRNAs (miRNAs) are a family of non-coding RNAs that are endogenous, short and consist of 18-25 nucleotides (8). MiRNAs serve as regulators of gene expression by binding to the 3'-untranslated regions (3'-UTRs) of their target mRNAs, which leads to either mRNA degradation or translational repression (9). miRNAs target mRNA with a semi-complimentary seed sequence (6-9 bp), which guides binding to the response elements; hence, one miRNA may have many potential targets because each seed sequence may correspond to many mRNA molecules (10). Growing evidence has shown that miRNAs play important roles in numerous cellular processes, including cell proliferation, apoptosis, cell cycle, differentiation, metabolism and stress response (11-13). The deregulation and aberrant expression of miRNAs has been reported in various human diseases, including cancer $(14,15)$. Downregulated miRNAs may normally act as tumor suppressor genes via the negative regulation of oncogenes (16), whereas upregulated miRNAs may play oncogenic roles during tumor development by repressing tumor suppressor genes (17). These data emphasise the importance of miRNAs in tumorigenesis and tumor development, suggesting that the investigation of miRNAs could provide novel therapeutic targets for anticancer treatment. 
miR-381, mapped to the $14 q 32.31$ locus, is aberrantly expressed in multiple types of human cancer (18-20). However, the expression pattern, biological roles and underlying mechanisms of miR-381 in EC are poorly understood. The current study aimed to detect the expression levels and functions of miR-381 in EC. The molecular mechanisms involved in the association of miR-381 with the proliferation and invasion of EC cells were also investigated.

\section{Materials and methods}

Tissue samples. This study protocol was approved by the Ethics Committee of the First Affiliated Hospital of Nanchang University. Written informed consent was obtained from each patient. A total of 45 paired EC tissues and corresponding adjacent normal endometrial tissues were collected from patients who underwent surgical resection at the Department of Obstetrics and Gynecology, The First Affiliated Hospital of Nanchang University between June 2014 and September 2016. All patients had not received chemotherapy or radiotherapy prior to surgery. Tissues were immediately frozen in liquid nitrogen and kept in liquid nitrogen until further analysis.

Cell culture and transfection. Human EC cell lines, HEC-1B, HEC-59, AN3CA and KLE, were purchased from the American Type Culture Collection (ATCC; Manassas, VA, USA). Ishikawa cell line was acquired from Sigma-Aldrich (Merck KGaA, Darmstadt, Germany). All cells were grown in Dulbecco's modified Eagle's medium (DMEM) along with $10 \%$ fetal bovine serum (FBS) (both from Gibco; Thermo Fisher Scientific, Inc., Waltham, MA, USA), $100 \mathrm{U} / \mathrm{ml}$ penicillin and $100 \mathrm{mg} / \mathrm{ml}$ streptomycin. Cells were kept in a humidified atmosphere of $5 \% \mathrm{CO}_{2}$ at $37^{\circ} \mathrm{C}$.

miR-381 mimics and miRNA mimics negative control (miR-NC) were obtained from GenePharma Co., Ltd. (Shanghai, China). Insulin-like growth factor receptor 1 (IGF-1R) overexpression plasmid (pcDNA3.1-IGF-1R) and empty plasmid (pcDNA3.1) were obtained from Shanghai Genechem Co., Ltd. (Shanghai, China). One day before transfection, cells were seeded into 6-well plates at a density of $60-70 \%$ confluence. Cell transfection was performed using Lipofectamine 2000 (Invitrogen; Thermo Fisher Scientific, Inc.), according to manufacturer's instructions.

RNA extraction and reverse transcription-quantitative polymerase chain reaction ( $R T-q P C R)$. Total RNA was extracted from tissues or cells using TRIzol reagent (Invitrogen; Thermo Fisher Scientific, Inc.) according to the manufacturer's instructions. To quantify miR-381 expression, total RNA was reverse transcribed into cDNA using TaqMan MicroRNA Reverse Transcription kit (Applied Biosystems; Thermo Fisher Scientific, Inc.). The qPCR was performed using TaqMan MicroRNA PCR kit (Applied Biosystems; Thermo Fisher Scientific, Inc.) on the Bio-Rad CFX96 Real-Time PCR system (Bio-Rad Laboratories, Inc., Hercules, CA, USA). U6 was used as an internal control for miR-381. To detect IGF-1R mRNA expression levels, cDNA was synthesized using PrimeScript RT Reagent kit, and then amplified by using SYBR Premix Ex $\mathrm{Taq}^{\mathrm{TM}}$ kit (both from Takara Biotechnology Co., Ltd., Dalian, China) with GAPDH as an internal control. Primers used in this assay were shown in Table I. Relative expression levels were analyzed using the $2^{-\Delta \Delta \mathrm{Ct}}$ method (21).

\section{3-(4,5-dimethyl-2-Thiazyl)-2,5-diphenyl-2H-tetrazolium bro-} mide (MTT) assay. Cell proliferation was assessed using the MTT assay (Sigma-Aldrich; Merck KGaA). Transfected cells were collected at $24 \mathrm{~h}$ post-transfection. Cells were then resuspend in DMEM medium with $10 \% \mathrm{FBS}$, and seeded into 96 -well plates at the density of $3 \times 10^{3}$ cells/well. After incubation for $0,24,48$ and $72 \mathrm{~h}$ respectively, MTT assay was performed following the manufacturer's protocols. Briefly, $10 \mu \mathrm{l}$ of MTT solution ( $5 \mathrm{mg} / \mathrm{ml}$ ) was added to each well and the plates were incubated at $37^{\circ} \mathrm{C}$ for $4 \mathrm{~h}$. The medium was then removed carefully, and $150 \mu$ I DMSO (Sigma-Aldrich; Merck KGaA) was added into each well. Finally, the optical density (OD) was detected at a wavelength of $490 \mathrm{~nm}$ using a microplate spectrophotometer (Multiskan FC; Thermo Fisher Scientific, Inc.). All assays were perfomred in quintuplicate through at least three independent experiments.

In vitro cell invasion assay. Matrigel-coated Transwell cell culture chambers (BD Biosciences, San Jose, CA, USA) were utilized to perform in vitro cell invasion assays. Transfected cells were harvested after $48 \mathrm{~h}$ incubation, re-suspended in FBS-free DMEM medium, and seeded into the upper chamber of Transwell chambers at a density of $5 \times 10^{4}$ cells/chamber. The lower chambers contained $500 \mu \mathrm{l}$ of DMEM medium supplemented with $10 \%$ FBS serving as the chemoattractant. After $24 \mathrm{~h}$ incubation at $37^{\circ} \mathrm{C}$ and $5 \% \mathrm{CO}_{2}$, the non-invasive cells were gently removed with cotton swabs. The invasive cells were fixed with $4 \%$ paraformaldehyde, stained in $0.5 \%$ crystal violet and wash with PBS. After drying in air, the invasive cells were photographed and counted under an inverted microscope (IX71; Olympus Corporation, Tokyo, Japan), with a magnification of x200, 5 randomly selected fields for each chamber.

Target prediction and luciferase reporter assay. To predict the potential targets of miR-381, bioinformatic analysis was performed using TargetScan (www.targetscan.org) and miRanda (www.microrna.org). IGF-1R was selected as the candidate target of miR-381. Luciferase reporter vectors, pmirGLO-IGF-1R-3'-UTR wild-type (Wt) and pmirGLO-IGF-1R-3'-UTR mutant (Mut), were syntesized and confirmed by GenePharma Co., Ltd. Cells were seeded into 24-well plates at the density of $2.0 \times 10^{5}$ cells/well. After incubation overnight, miR-381 mimics or miR-NC was transfected into cells followed by cotransfection with pmirGLO-IGF-1R-3'-UTR Wt or pmirGLO-IGF-1R-3'-UTR Mut, using Lipofectamine 2000, following the manufacturer's instructions. After incubation $48 \mathrm{~h}$, cell lysates were collected and luciferase activities were examiend using the Dual-Luciferase Reporter Assay system (Promega, Manheim, Germany) in accordance with the manufacturer's suggestions. Each experiment was repeated at least three times.

Western blotting analysis. Total protein Total protein was extracted form tissues or cells using ice-cold radioimmunoprecipitation assay buffer containing protease inhibitors, following by quantification with a BCA protein assay kit (both from Beyotime Institute of Biotechnology, Jiangsu, Haimen, 
Table I. Primers for reverse transcription-quantitative polymerase chain reaction.

\begin{tabular}{ll}
\hline Gene & \multicolumn{1}{c}{ Sequences $\left(5^{\prime} \rightarrow 3^{\prime}\right)$} \\
\hline $\begin{array}{l}\text { microRNA-381 } \\
\text { Forward } \\
\text { Reverse }\end{array}$ & $\begin{array}{l}\text { GGAGCCTATACAAGGGCAAGC } \\
\text { GCGAGCACAGAATAAATACGACT }\end{array}$ \\
U6 & CACTA \\
Forward & CTCGCTTCGGCAGCACATATACT \\
Reverse & ACGCTTCACGAATTTGCGTGTC \\
IGF-1R & \\
Forward & AGGATATTGGGCTTTACAACCTG \\
Reverse & GAGGTAACAGAGGTCAGCATTTT \\
GAPDH & \\
Forward & AGAAGGCTGGGGCTCATTTG \\
Reverse & AGGGGCCTCCACAGTCTTC \\
\hline
\end{tabular}

IGF-1R, insulin-like growth factor 1.

Table II. Correlation of microRNA-381 expression with different clinicopathological factors of endometrial carcinoma.

\begin{tabular}{|c|c|c|c|c|}
\hline $\begin{array}{l}\text { Clinicopathologic } \\
\text { factors }\end{array}$ & $\begin{array}{l}\text { No. } \\
\text { of } \\
\text { cases }\end{array}$ & $\begin{array}{c}\text { Low } \\
\text { miR-381 } \\
\text { group }\end{array}$ & $\begin{array}{l}\text { High } \\
\text { miR-381 } \\
\text { group }\end{array}$ & P-value \\
\hline Age, years & & & & 0.420 \\
\hline$<50$ & 17 & 10 & 7 & \\
\hline$\geq 50$ & 28 & 13 & 15 & \\
\hline Histological grade & & & & 0.286 \\
\hline Well and moderate & 25 & 11 & 14 & \\
\hline Poor & 20 & 12 & 8 & \\
\hline FIGO stage & & & & 0.001 \\
\hline I-II & 21 & 5 & 16 & \\
\hline III-IV & 24 & 18 & 6 & \\
\hline $\begin{array}{l}\text { Lymph node } \\
\text { metastasis }\end{array}$ & & & & 0.004 \\
\hline No & 25 & 8 & 17 & \\
\hline Yes & 20 & 15 & 5 & \\
\hline $\begin{array}{l}\text { Myometrial } \\
\text { invasion }\end{array}$ & & & & 0.021 \\
\hline No & 27 & 10 & 17 & \\
\hline Yes & 18 & 13 & 5 & \\
\hline
\end{tabular}

FIGO, International Federation of Gynecology and Obstetrics.

China). Equal amounts of protein were separated on $10 \%$ SDS-polyacrylamide gel and electrotransferred to polyvinylidene difluoride membranes (Sigma; Merck KGaA). Following blocking with $5 \%$ non-fat milk in Tris-buffered saline with $0.1 \%$ Tween-20 (TBST), the membranes were incubated overnight at $4^{\circ} \mathrm{C}$ with the primary antibody. Subsequently,
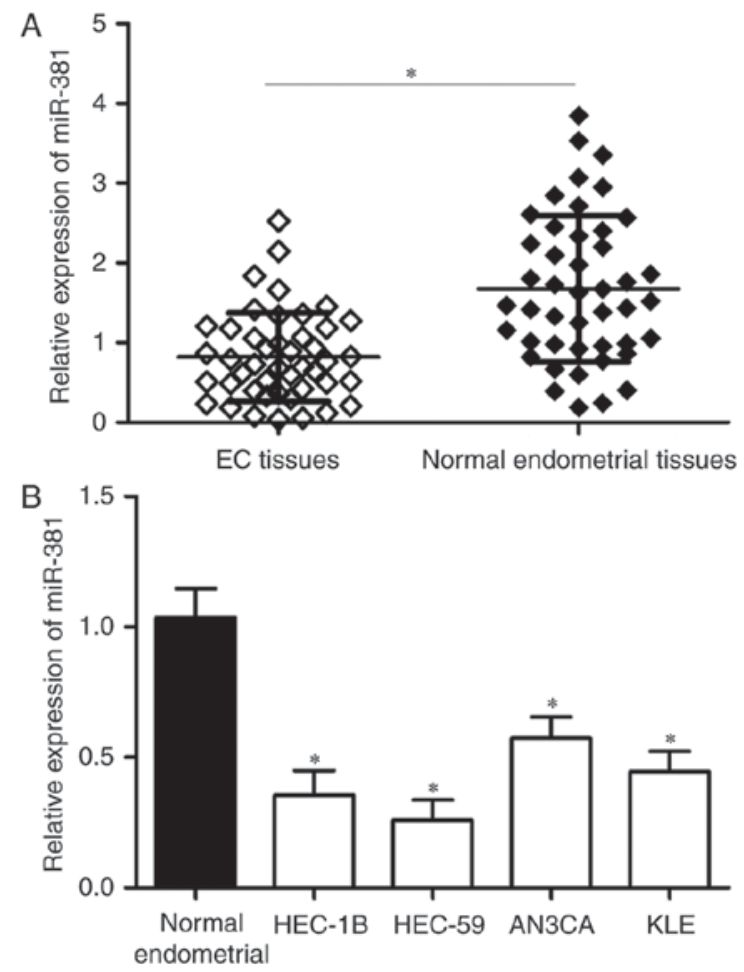

Figure 1. Suppressed expression of miR-381 in EC tissues and cell lines. (A) RT-qPCR analysis of miR-381 expression in 45 paired EC tissues and corresponding adjacent normal endometrial tissues. ${ }^{*} \mathrm{P}<0.05$ compared with adjacent normal endometrial tissues. (B) miR-381 expression levels in EC cell lines (HEC-1B, HEC-59, AN3CA and KLE) as detected by RT-qPCR. ${ }^{*} \mathrm{P}<0.05$ compared with adjacent normal endometrial tissues. EC, endometrial carcinoma.

the membranes were washed with TBST for three times, and probed with a goat anti-mouse horseradish peroxidase (HRP)-conjugated secondary antibody (1:5,000 dilution; sc-2005; Santa Cruz Biotechnology, Inc., Dallas, TX, USA) at room temperature for $1 \mathrm{~h}$. Immunoreactive protein bands were visualised using an enhanced chemiluminescence system (GE Healthcare Life Sciences, Chalfont, UK) according to the manufacturer's protocol. The intensity of protein bands was analyzed with Quantity One software version 4.62 (Bio-Rad Laboratories, Inc., Hercules, CA, USA). Primary antibodies used in this research were mouse anti-human monoclonal IGF-1R antibody (1:1,000 dilution; sc-81464; Santa Cruz Biotechnology, Inc.), mouse anti-human monoclonal extracellular signal-regulated kinase (ERK; sc-514302; 1:1,000 dilution), mouse anti-human monoclonal p-ERK (sc-81492; 1:1,000 dilution), mouse anti-human monoclonal p-AKT antibody (1:1,000 dilution; sc-271966), mouse anti-human monoclonal AKT antibody (1:1,000 dilution; sc-81434), and mouse anti-human monoclonal GAPDH antibody (1:1,000 dilution; sc-69778) (all from Santa Cruz Biotechnology, Inc.). GAPDH was used as a loading control.

Statistical analysis. Data were expressed as the mean \pm SD. Statistical analysis was performed with Student's t-test or one-way ANOVA using SPSS software version 13.0 (SPSS, Inc., Chicago, IL, USA). Newman-Keuls method was used to compare between two groups in multiple groups study. A P-value $<0.05$ was considered statistically significant. 

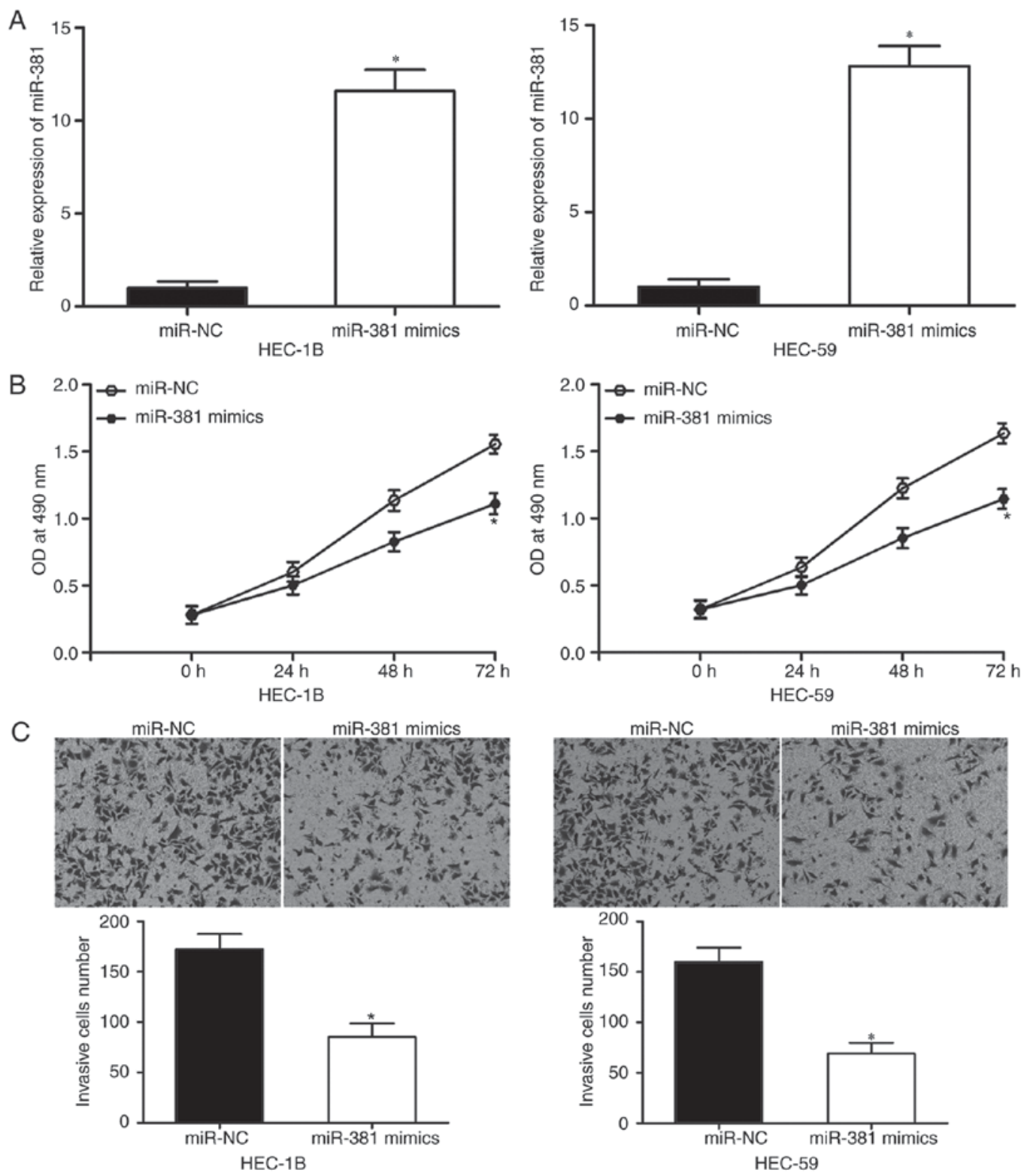

Figure 2. Suppression of EC cell proliferation and invasion in vitro via expression restoration of miR-381. (A) RT-qPCR analysis of HEC-1B and HEC-59 cells transfected with miR-381 mimics or miR-NC for miR-381 expression. " $\mathrm{P}<0.05$ compared with miR-NC. (B) Cell proliferation of HEC-1B and HEC-59 cells as determined by MTT assay after transfection with miR-381 mimics or miR-NC. "P<0.05 compared with miR-NC. (C) In vitro cell invasion assay of the effect of miR-381 over-expression on the cell invasion activities of HEC-1B and HEC-59 cells. " $\mathrm{P}<0.05$ compared with miR-NC. EC, endometrial carcinoma.

\section{Results}

miR-381 is frequently downregulated in EC tissues and cell lines. The expression levels of miR-381 in 45 paired EC tissues and corresponding adjacent normal endometrial tissues were determined by RT-qPCR. Results showed that miR-381 expression was significantly lower in the EC tissues than in the adjacent normal endometrial tissues (Fig. 1A , P <0.05). EC patients were divided into two groups to analyse the association between miR-381 and the clinicopathological features of EC. The grouping was based on the median relative miR-381 expression value that was used for the cut-off. As shown in Table II, the expression level of miR-381 correlated with the FIGO stage $(\mathrm{P}=0.001)$, lymph nodes metastasis $(\mathrm{P}=0.004)$ and myometrial invasion $(\mathrm{P}=0.021)$ of EC. However, miR-381 expression showed no significant correlation with other clinicopathological factors, including age $(\mathrm{P}=0.420)$ and histological grade $(\mathrm{P}=0.286)$.

The miR-381 expression in four EC cell lines (HEC-1B, HEC-59, AN3CA and KLE) was also examined. As shown in Fig. 1B, miR-381 was downregulated in the EC cell lines compared with the adjacent normal endometrial tissues. These results suggest that miR-381 is important in EC progression.

miR-381 overexpression inhibits the proliferation and invasion of EC cells. HEC-1B and HEC-59 cells were transfected with miR-381 mimics or miR-NC to elucidate the biological roles of miR-381 in EC. As shown in Fig. 2A, miR-381 mimics transfection in HEC-1B and HEC-59 cells markedly increased the expression levels of miR-381 as compared with 

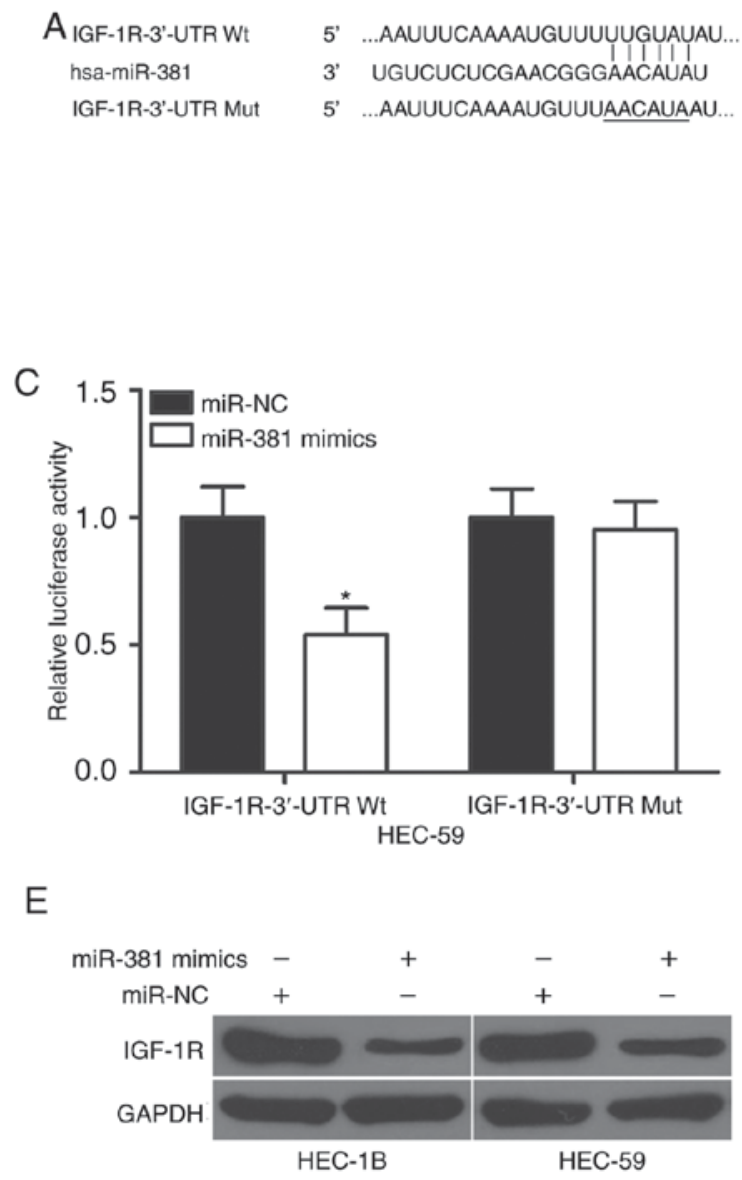
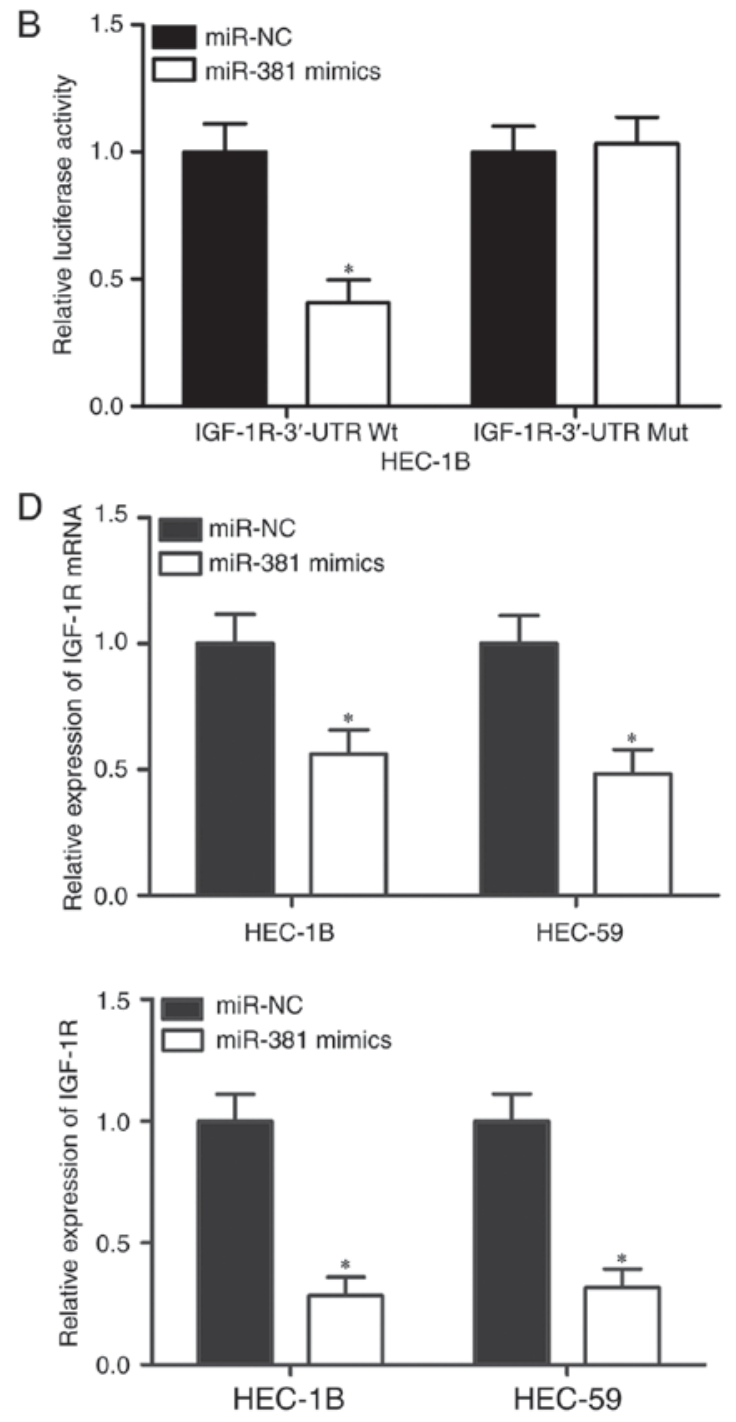

Figure 3. IGF-1R is a direct target of miR-381 in EC. (A) Putative miR-381-binding sites in the 3'-UTR of IGF-1R and the corresponding mutant binding sites. (B and C) HEC-1B and HEC-59 cells co-transfected with miR-381 mimics or miR-NC and pmirGLO-IGF-1R-3'-UTR Wt or pmirGLO-IGF-1R-3'-UTR Mut. The relative firefly luciferase activities were measured after transfection for $48 \mathrm{~h}$. ${ }^{*} \mathrm{P}<0.05$ compared with miR-NC. (D and E) mRNA and protein expression levels of IGF-1R in HEC-1B and HEC-59 cells as determined by RT-qPCR and western blot analyses after transfection with miR-381 mimics or miR-NC. "P<0.05 compared with miR-NC. IGF-1R, insulin-like growth factor 1; EC, endometrial carcinoma; 3'-UTR, 3'-untranslated region.

miR-NC transfection $(\mathrm{P}<0.05)$. MTT assay revealed that the upregulation of miR-381 significantly inhibited the proliferation of both HEC-1B and HEC-59 cells as compared with the miR-NC group (Fig. 2B, P <0.05). Furthermore, in vitro cell invasion assay revealed that miR-381 overexpression reduced the invasion capacities of HEC-1B and HEC-59 cells (Fig. 2C, $\mathrm{P}<0.05)$. These results suggest that miR-381 acts as a tumor suppressor in EC progression.

miR-381 directly targets the IGF-1R in EC. Bioinformatics analysis was performed to analyse the potential targets of miR-381 and explore the mechanisms underlying the regulative role miR-381 in EC. IGF-1R harbouring a miR-381-binding site (Fig. 3A) was chosen for further validation because of its role in $\mathrm{EC}$ formation and progression $(22,23)$. Luciferase reporter assays were performed to confirm this hypothesis and examine whether miR-381 interacts directly with the 3'-UTR of IGF-1R. HEC-1B and HEC-59 cells were transfected with miR-381 mimics or miR-NC and pmirGLO-IGF-1R-3'-UTR
Wt or pmirGLO-IGF-1R-3'-UTR Mut. The co-transfection of miR-381 and wild-type IGF-1R 3'UTR significantly reduced the luciferase activities (Fig. $3 \mathrm{~B}$ and $\mathrm{C}, \mathrm{P}<0.05$ ). However, the co-transfection of the mutant IGF-1R 3'-UTR and miR-381 mimics did not affect the luciferase activities in both HEC-1B and HEC-59 cells. Furthermore, RT-qPCR and western blot analyses were conducted to detect the mRNA and protein expression levels of IGF-1R in HEC-1B and HEC-59 cells after transfection with miR-381 mimics or miR-NC. As shown in Fig. 3D and E, the restored expression of miR-381 reduced the IGF-1R expression in HEC-1B and HEC-59 cells at the mRNA $(\mathrm{P}<0.05)$ and protein $(\mathrm{P}<0.05)$ levels. In summary, these results suggest that miR-381 directly targets the 3'-UTR of IGF-1R and thereby represses the gene expression.

$I G F-1 R$ is upregulated in EC tissues and inversely correlated with miR-381 levels. To further determine the relationship between miR-381 and IGF-1R, we measured their expression 

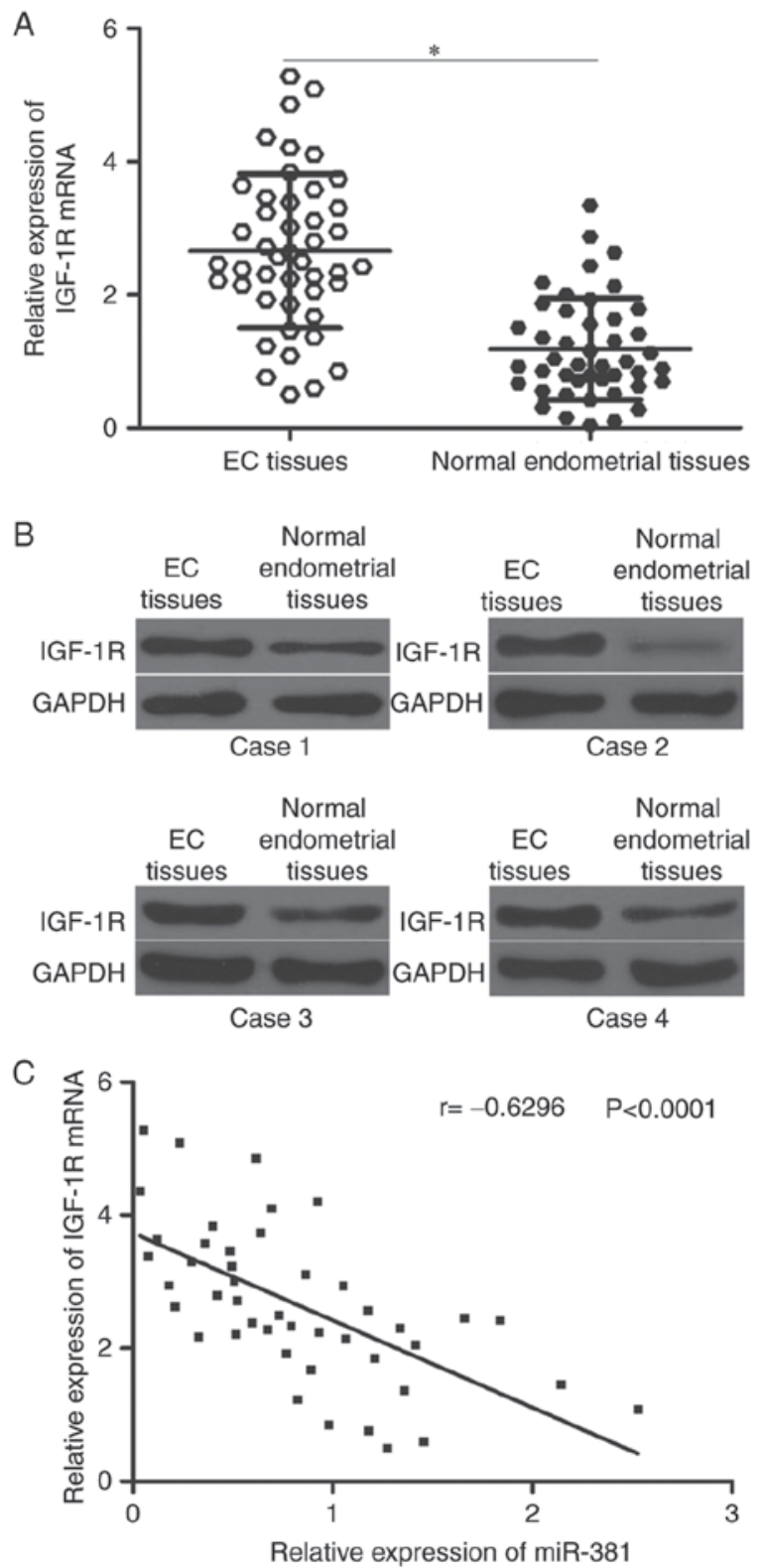

Figure 4. Inverse correlation between miR-381 and IGF-1R expression levels in EC tissues. (A) RT-qPCR for the detection of IGF-1R mRNA expression in 45 paired EC tissues and their corresponding adjacent normal endometrial tissues. ${ }^{*} \mathrm{P}<0.05$ compared with adjacent normal endometrial tissues. (B) Western blot analysis of IGF-1R protein expression in EC tissues and corresponding adjacent normal endometrial tissues. (C) Negative correlation of IGF-1R mRNA expression in EC tissues with miR-381 expression. $\mathrm{r}=-0.6296, \mathrm{P}<0.0001$. IGF-1R, insulin-like growth factor 1; EC, endometrial carcinoma.

levels in EC tissues and corresponding adjacent normal endometrial tissues. Results showed that the mRNA expression of IGF-1R was significantly higher in EC tissues than in corresponding adjacent normal endometrial tissues (Fig. 4A, $\mathrm{P}<0.05)$. Western blot analysis also indicated that the protein expression levels of IGF-1R were upregulated in EC tissues (Fig. 4B). Furthermore, Spearman's correlation analysis revealed an inverse association between miR-381 and IGF-1R mRNA levels in EC tissues (Fig. 4C; $r=-0.6296, \mathrm{P}<0.0001$ ).

Upregulation of IGF-1R counteracts the effects of miR-381 in EC cells. A rescue experiment was performed to examine whether IGF-1R mediates the tumor-suppressing roles of miR-381 in EC cells. HEC-1B and HEC-59 cells were transfected with miR-381 mimics in the presence or absence of pcDNA3.1-IGF-1R. Western blot analysis showed that miR-381 overexpression reduced the protein expression level of IGF-1R, whereas pcDNA3.1 co-transfection can recover the IGF-1R expression in HEC-1B and HEC-59 cells (Fig. 5A, $\mathrm{P}<0.05)$. MTT and in vitro invasion assays revealed that the resumed expression of IGF-1R rescued the suppressive effects of miR-381 on the proliferation (Fig. 5B, $\mathrm{P}<0.05)$ and invasion (Fig. 5C, $\mathrm{P}<0.05$ ) of HEC-1B and HEC-59 cells. These results provide further evidence that miR-381 partially exerts its tumor-suppressing roles in EC by negatively regulating IGF-1R.

miR-381 targets IGF-1R to inactivate the AKT and ERK signalling pathway. IGF-1R is involved in the AKT and ERK signalling pathways (24-26). Therefore, we hypothesised that miR-381 targets IGF-1R to affect the AKT and ERK signalling pathway in EC cells. AKT, p-AKT, ERK and p-ERK were detected in HEC-1B and HEC-59 cells transfected with miR-NC, miR-381 mimics or miR-381 mimics+pcDNA3.1-IGF-1R. As shown in Fig. 6, the ectopic expression of miR-381 reduced the expression levels of p-AKT and p-ERK in HEC-1B and HEC-59 cells as compared with the cells transfected with miR-NC; however, the total AKT and ERK levels did not significantly change. In addition, the expression levels of p-AKT and p-ERK were recovered in HEC-1B and HEC-59 cells after transfection with miR-381 mimics and pcDNA3.1-IGF-1R. These results indicate that miR-381 acts as a tumor suppressor in EC by directly targeting IGF-1R and indirectly regulating the AKT and ERK signalling pathways.

\section{Discussion}

miRNAs serve as oncogenes or tumor suppressors in human cancers and play important roles in tumorigenesis and tumor development by regulating various processes $(27,28)$. Thus, further investigation of the miRNAs involved in EC occurrence and progression may contribute to the development of effective therapeutic strategies for patients with this disease. In this study, we found that miR-381 was downregulated in EC tissues and cell lines. The low expression levels of miR-381 correlated with the FIGO stage, lymph nodes metastasis and myometrial invasion of EC. The overexpression of miR-381 significantly inhibited the proliferation and invasion of EC cells in vitro. Moreover, IGF-1R was validated as a direct target of miR-381. The upregulation of miR-381 targeted IGF-1R to inactivate the AKT and ERK signalling pathways. These results suggest that miR-381 can be further developed as a novel prognostic biomarker for EC and is potentially a therapeutic target.

miR-381 is aberrantly expressed in several types of human cancer. For example, miR-381 is significantly downregulated in lung adenocarcinoma. Low miR-381 expression levels correlate with poor prognosis for patients with lung adenocarcinoma (29). In colorectal cancer, miR-381 shows low expression in tumor tissues and is associated with distant metastasis and TNM stage (30). In gastric cancer, the expression levels of 
A
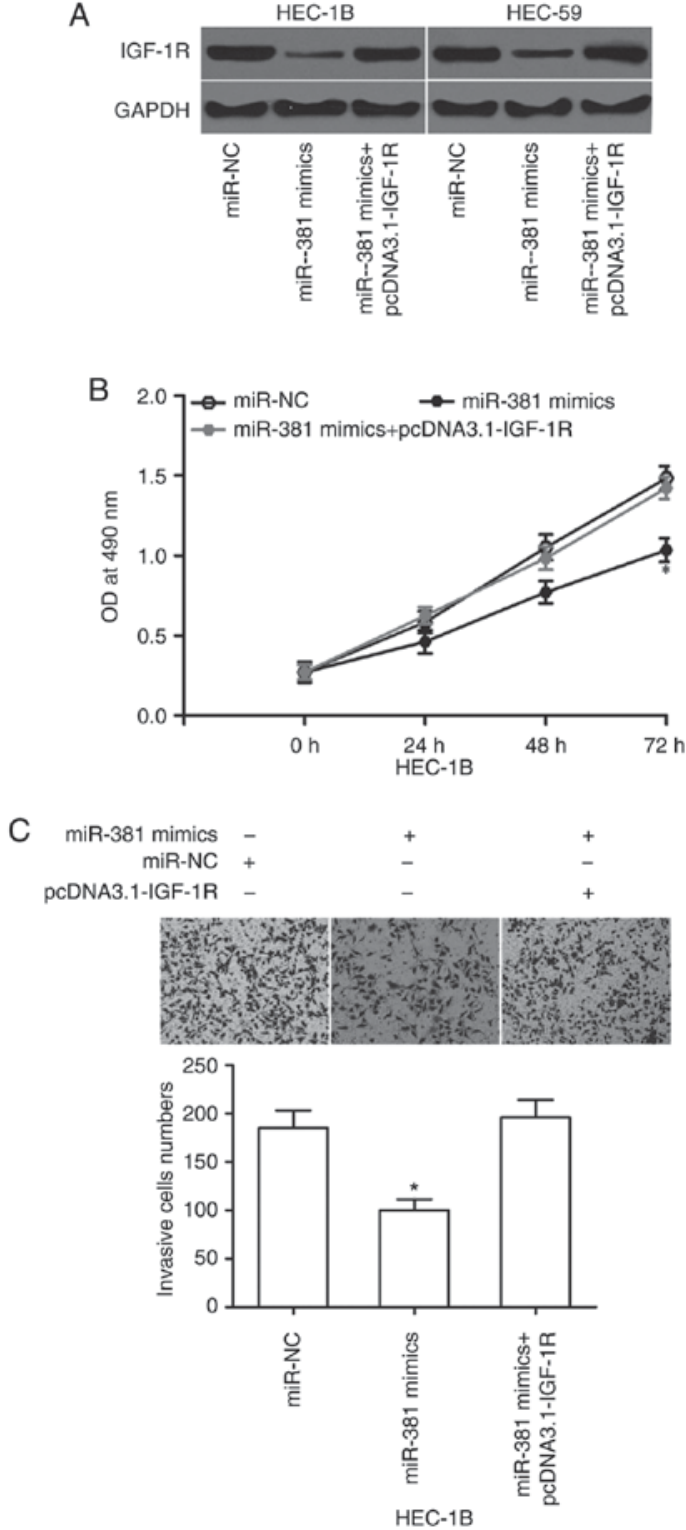
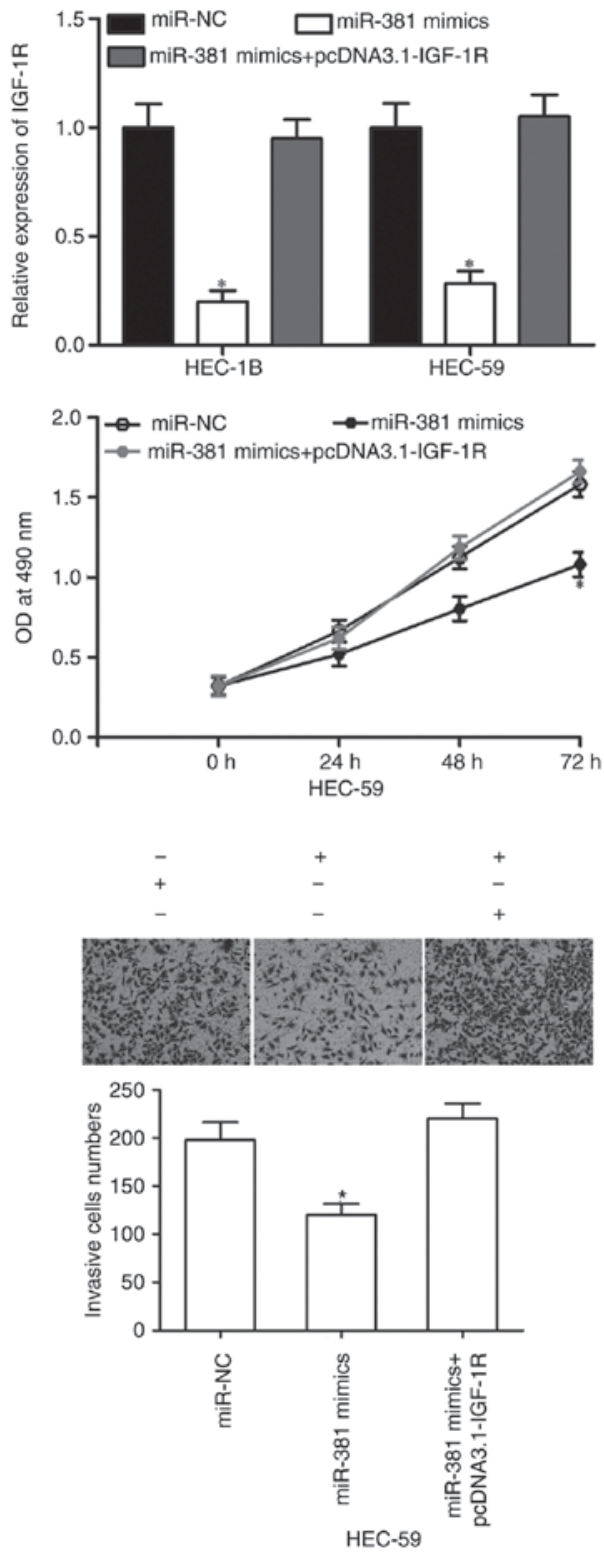

Figure 5. Resumed expression of IGF-1R rescues the suppressive effects of miR-381 in EC cells. (A) HEC-1B and HEC-59 cells transfected with miR-NC, miR-381 mimics or miR-381 mimics ${ }^{+}$pcDNA3.1-IGF-1R. After transfection, western blot analysis was performed to determine IGF-1R expression. ${ }^{*} \mathrm{P}<0.05$ compared with miR-NC and miR-381 mimics ${ }^{+}$pcDNA3.1-IGF-1R. (B and C) MTT and in vitro invasion assays of the proliferation and invasion of HEC-1B and HEC-59 cells after transfection with miR-NC, miR-381 mimics or miR-381 mimics+pcDNA3.1-IGF-1R. "P<0.05 compared with miR-NC and miR-381 mimics+pcDNA3.1-IGF-1R. IGF-1R, insulin-like growth factor 1; EC, endometrial carcinoma..

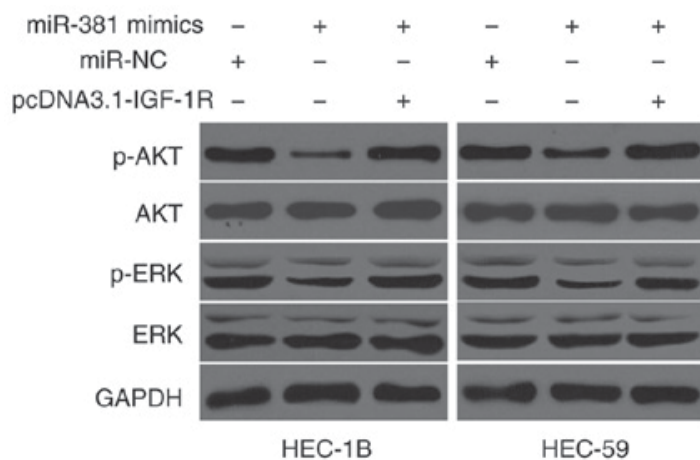

Figure 6. miR-381-induced inhibition of the AKT and ERK signalling pathways in EC. Western blot analysis of AKT, p-AKT, ERK and p-ERK expression levels in HEC-1B and HEC-59 cells transfected with miR-NC, miR-381 mimics or miR-381 mimics+pcDNA3.1-IGF-1R. IGF-1R, insulin-like growth factor 1; EC, endometrial carcinoma; ERK, extracellular signal-regulated kinase.
miR-381 are low in tumor tissues and cell lines. In addition, miR381 expression is associated with lymph node metastasis, advanced tumor stage and poor prognosis (31). miR-381 is also downregulated in oral squamous cell carcinoma (18), ovarian cancer (19), oesophageal squamous cell carcinoma (20), hepatocellular carcinoma (32) and breast cancer (33). However, miR-381 is upregulated in osteosarcoma tissues. Patients with relatively low miR-381 expression have longer survival time than those with high miR-381 expression (34). These findings suggest that the expression pattern of miR-381 is tissue-specific, and the aberrant expression of miR-381 is a potential prognostic factor in these cancer types.

miR-381 plays tumor-suppressing roles in the formation and progression of several types of tumors. For instance, Rothschild et al (29) reported that miR-381 overexpression 
suppresses cell migration and invasion in lung adenocarcinoma Chen et al (35) found that miR-381 upregulation attenuates the cell invasion abilities and increases the chemosensitivity of renal cancer cells to 5-FU. He and Liang et al $(30,36)$ revealed that the enforced expression of miR-381 represses cell growth, metastasis and epithelial-mesenchymal transition in colorectal cancer. Cao et al found that the restoration of miR-381 expression reduces cell proliferation and motility in vitro and in vivo and downregulates the epithelial-mesenchymal transition phenotype in gastric cancer (31). Yang et al (18) showed that the resumption of miR-381 expression inhibits the proliferation and cell cycle progression while induces the apoptosis of oral squamous cell carcinoma cells. miR-381 also acts as a tumor suppressor in ovarian cancer (19), hepatocellular carcinoma (32) and breast cancer (33,37). However, miR-381 functions as an oncogene in osteosarcoma. The re-expression of miR-381 promotes the proliferation and invasion of osteosarcoma cells and reduces cisplatin sensitivity (34). miR-381 overexpression increases the growth and reduces the chemosensitivity of glioma cells to temozolomide $(38,39)$. These conflicting findings reveal that miR-381 acts as either an oncogene in certain types of cancer or as a tumor suppressor in others, which can be explained by the 'imperfect complementarity' of the interactions between miRNAs and their target genes (40). These findings also suggest that miR-381 is a therapeutic target for patients with these cancer types.

Some direct targets of miR-381 include WEE1 (35), CBP (41), $\beta$-catenin (41), LEF-1 (41) in renal cancer, Twist1 (30), LRH-1 (36) in colorectal cancer, LRRC4 in osteosarcoma, TMEM16A (31) in gastric cancer, FGFR2 (18) in oral squamous cell carcinoma and YY1 (19) in ovarian cancer. In the current study, IGF-1R was identified as a novel direct target gene of miR-381 in EC. IGF-1R, a member of the receptor tyrosine kinase family, contains two extracellular $\alpha$ subunits and two $\beta$ subunits $(42,43)$. The highly expressed IGF-1R has been documented in numerous malignancies, including hepatocellular carcinoma (44), lung cancer (45), prostate cancer (46), gastric cancer (47), colorectal cancer (48) and bladder cancer (49). IGF-1R functions as a key oncogene in the development and maintenance of cancer through the regulation of cell growth, cycle, apoptosis, migration, invasion and distant metastasis (50-52). IGF-1R is also upregulated in EC tissues and cell lines. The high expression level of IGF-1R is correlated with lymph node metastasis and tumor stage $(23,53)$. IGF-1R knockdown significantly inhibits the proliferation, induces the apoptosis in vitro and reduces the tumorigenesis in vivo of EC cells (22). Combined with the present findings, the miR-381/IGF-1R pathway shows a potential to be investigated as a therapeutic strategy for patients with EC.

In conclusion, our data provide new evidence supporting the tumor-suppressive roles of miR-381 in EC. We also revealed that IGF-1R is a novel target of miR-381 in EC. In the future, miR-381 can be developed as a novel prognostic biomarker and therapeutic target for the treatment of EC. In our following experiments, we will focus on the upstream regulation mechanism of miR-381 in EC.

\section{References}

1. Torre LA, Bray F, Siegel RL,Ferlay J,Lortet-Tieulent J and Jemal A Global cancer statistics, 2012. CA Cancer J Clin 65: 87-108, 2015.
2. Jin F, Devesa SS, Chow WH, Zheng W, Ji BT, Fraumeni JF Jr and Gao YT: Cancer incidence trends in urban Shanghai, 1972-1994: An update. Int J Cancer 83: 435-440, 1999.

3. Dahlgren E, Friberg LG, Johansson S, Lindström B, Odén A, Samsioe G and Janson PO: Endometrial carcinoma; ovarian dysfunction-a risk factor in young women. Eur J Obstet Gynecol Reprod Biol 41: 143-150, 1991.

4. Chen YL, Wang KL, Chen MY, Yu MH, Wu CH, Ke YM, Chen YJ, Chang YY, Hsu KF and Yen MS: Risk factor analysis of coexisting endometrial carcinoma in patients with endometrial hyperplasia: A retrospective observational study of Taiwanese Gynecologic Oncology Group. J Gynecol Oncol 24: 14-20, 2013.

5. Wild PJ, Ikenberg K, Fuchs TJ, Rechsteiner M, Georgiev S, Fankhauser N, Noske A, Roessle M, Caduff R, Dellas A, et al: p53 suppresses type II endometrial carcinomas in mice and governs endometrial tumour aggressiveness in humans. EMBO Mol Med 4: 808-824, 2012.

6. Vale CL, Tierney J, Bull SJ and Symonds PR: Chemotherapy for advanced, recurrent or metastatic endometrial carcinoma. Cochrane Database Syst Rev 15: CD003915, 2012.

7. Boll D, Verhoeven RH, van der Aa MA, Pauwels P, Karim-Kos HE, Coebergh JW and van Doorn HC: Incidence and survival trends of uncommon corpus uteri malignancies in the Netherlands, 1989-2008. Int J Gynecol Cancer 22: 599-606, 2012.

8. Croce CM and Calin GA: miRNAs, cancer, and stem cell division. Cell 122: 6-7, 2005.

9. Moreno-Moya JM, Vilella F and Simoón C: MicroRNA: Key gene expression regulators. Fertil Steril 101: 1516-1523, 2014.

10. Dang X, Ma A, Yang L, Hu H, Zhu B, Shang D, Chen T and Luo Y: MicroRNA-26a regulates tumorigenic properties of EZH2 in human lung carcinoma cells. Cancer Genet 205: 113-123, 2012.

11. Bartel DP: MicroRNAs: Genomics, biogenesis, mechanism and function. Cell 116: 281-297, 2004.

12. Shukla GC, Singh J and Barik S: MicroRNAs: Processing, maturation, target recognition and regulatory functions. Mol Cell Pharmacol 3: 83-92, 2011

13. Bartel DP: MicroRNAs: Target recognition and regulatory functions. Cell 136: 215-233, 2009.

14. Vandenboom Ii TG, Li Y, Philip PA and Sarkar FH: MicroRNA and cancer: Tiny molecules with major implications. Curr Genomics 9: 97-109, 2008.

15. Segura MF, Hanniford D, Menendez S, Reavie L, Zou X, Alvarez-Diaz S, Zakrzewski J, Blochin E, Rose A, Bogunovic D, et al: Aberrant miR-182 expression promotes melanoma metastasis by repressing $\mathrm{FOXO} 3$ and microphthalmia-associated transcription factor. Proc Natl Acad Sci USA 106: 1814-1819, 2009.

16. Wu D, Zhou Y, Pan H, Zhou J, Fan Y and Qu P: microRNA-99a inhibiting cell proliferation, migration and invasion by targeting fibroblast growth factor receptor 3 in bladder cancer. Oncol Lett 7: 1219-1224, 2014

17. Liang C, Zhang X, Wang HM, Liu XM, Zhang XJ, Zheng B, Qian GR and Ma ZL: MicroRNA-18a-5p functions as an oncogene by directly targeting IRF2 in lung cancer. Cell Death Dis 8: e2764, 2017.

18. Yang X, Ruan H, Hu X, Cao A and Song L: miR-381-3p suppresses the proliferation of oral squamous cell carcinoma cells by directly targeting FGFR2. Am J Cancer Res 7: 913-922, 2017.

19. Xia B, Li H, Yang S, Liu T and Lou G: miR-381 inhibits epithelial ovarian cancer malignancy via YY1 suppression. Tumour Biol 37: 9157-9167, 2016.

20. Zhou S, Ye W, Ren J, Shao Q, Qi Y, Liang J and Zhang M: MicroRNA-381 increases radiosensitivity in esophageal squamous cell carcinoma. Am J Cancer Res 5: 267-277, 2014.

21. Livak KJ and Schmittgen TD: Analysis of relative gene expression data using real-time quantitative PCR and the 2(-Delta Delta C(T)) method. Methods 25: 402-408, 2001.

22. Shu S, Li X, Yang Y, Zhang Y,Li T, Liang C and Wan J: Inhibitory effect of siRNA targeting IGF-1R on endometrial carcinoma. Int Immunopharmacol 11: 244-249, 2011.

23. Pengchong $\mathrm{H}$ and Tao $\mathrm{H}$ : Expression of IGF-1R, VEGF-C and D2-40 and their correlation with lymph node metastasis in endometrial adenocarcinoma. Eur J Gynaecol Oncol 32: 660-664, 2011.

24. Chen G, Fang T, Huang Z, Qi Y, Du S, Di T, Lei Z, Zhang X and Yan W: MicroRNA-133a inhibits osteosarcoma cells proliferation and invasion via targeting IGF-1R. Cell Physiol Biochem 38: 598-608, 2016. 
25. Ding WZ, Ni QF, Lu YT, Kong LL, Yu JJ, Tan LW and Kong LB: MicroRNA-497 regulates cell proliferation in hepatocellular carcinoma. Oncol Lett 11: 1081-1088, 2016

26. Shimizu M, Shirakami Y, Sakai H, Tatebe H, Nakagawa T, Hara Y, Weinstein IB and Moriwaki H: EGCG inhibits activation of the insulin-like growth factor (IGF)/IGF-1 receptor axis in human hepatocellular carcinoma cells. Cancer Lett 262: 10-18, 2008.

27. Hou XW, Sun X, Yu Y, Zhao HM, Yang ZJ, Wang X and Cao XC: miR-361-5p suppresses lung cancer cell lines progression by targeting FOXM1. Neoplasma 64: 526-534, 2017.

28. Li P, Wang X, Shan Q, Wu Y and Wang Z: MicroRNA-130b promotes cell migration and invasion by inhibiting peroxisome proliferator-activated receptor- $\gamma$ in human glioma. Oncol Lett 13 2615-2622, 2017.

29. Rothschild SI, Tschan MP, Jaggi R, Fey MF, Gugger M and Gautschi O: MicroRNA-381 represses ID1 and is deregulated in lung adenocarcinoma. J Thorac Oncol 7: 1069-1077, 2012.

30. He X, Wei Y, Wang Y, Liu L, Wang W and Li N: miR-381 functions as a tumor suppressor in colorectal cancer by targeting Twist1. Onco Targets Ther 9: 1231-1239, 2016.

31. Cao Q, Liu F, Ji K, Liu N, He Y, Zhang W and Wang L: MicroRNA-381 inhibits the metastasis of gastric cancer by targeting TMEM16A expression. J Exp Clin Cancer Res 36: 29, 2017.

32. Zhang Q, Zhao S, Pang X and Chi B: MicroRNA-381 suppresses cell growth and invasion by targeting the liver receptor homolog-1 in hepatocellular carcinoma. Oncol Rep 35: 1831-1840, 2016.

33. Ming J, Zhou Y, Du J, Fan S, Pan B, Wang Y, Fan L and Jiang J: miR-381 suppresses $\mathrm{C} / \mathrm{EBP} \alpha$-dependent $\mathrm{Cx} 43$ expression in breast cancer cells. Biosci Rep 35: e00266, 2015

34. Li Y, Zhao C, Yu Z, Chen J, She X, Li P, Liu C, Zhang Y, Feng J, $\mathrm{Fu} \mathrm{H}$, et al: Low expression of miR-381 is a favorite prognosis factor and enhances the chemosensitivity of osteosarcoma. Oncotarget 7: 68585-68596, 2016.

35. Chen B, Duan L, Yin G, Tan J and Jiang X: miR-381, a novel intrinsic WEE1 inhibitor, sensitizes renal cancer cells to 5-FU by up-regulation of $\mathrm{Cdc} 2$ activities in 786-O. J Chemother 25 229-238, 2013

36. Liang Y, Zhao Q, Fan L, Zhang Z, Tan B, Liu Y and Li Y: Down-regulation of microRNA-381 promotes cell proliferation and invasion in colon cancer through up-regulation of LRH-1. Biomed Pharmacother 75: 137-141, 2015.

37. Xue Y,Xu W,Zhao W, Wang W,Zhang D and Wu P: miR-381 inhibited breast cancer cells proliferation, epithelial-to-mesenchyma transition and metastasis by targeting CXCR4. Biomed Pharmacother 86: 426-433, 2017.

38. Wang Z, Yang J, Xu G, Wang W, Liu C, Yang H, Yu Z, Lei Q, Xiao L, Xiong J, et al: Targeting miR-381-NEFL axis sensitizes glioblastoma cells to temozolomide by regulating stemness factors and multidrug resistance factors. Oncotarget 6: 3147-3164, 2015.

39. Tang H, Wang Z, Liu Q, Liu X, Wu M and Li G: Disturbing miR-182 and -381 inhibits BRD7 transcription and glioma growth by directly targeting LRRC4. PLoS One 9: e84146, 2014
40. Yu Z, Ni L, Chen D, Zhang Q, Su Z, Wang Y, Yu W, Wu X, Ye J, Yang S, et al: Identification of miR-7 as an oncogene in renal cell carcinoma. J Mol Histol 44: 669-677, 2013.

41. Chen B and Liu B: miRNA-381 inhibits the invasion of renal carcinoma and the underlying mechanisms. Zhong Nan Da Xue Xue Bao Yi Xue Ban 40: 1053-1059, 2015.

42. LeRoith D and Helman L: The new kid on the block (ade) of the IGF-1 receptor. Cancer Cell 5: 201-202, 2004

43. Pollak M: Insulin and insulin-like growth factor signalling in neoplasia. Nat Rev Cancer 8: 915-928, 2008.

44. E C, Li J, Shao D, Zhang D, Pan Y, Chen L and Zhang X: The insulin-like growth factor-I receptor inhibitor picropodophyllin-induced selective apoptosis of hepatocellular carcinoma cell through a caspase-dependent mitochondrial pathway. Oncol Res 21: 103-110, 2013

45. Yeo CD, Park KH, Park CK, Lee SH, Kim SJ, Yoon HK, Lee YS, Lee EJ, Lee KY and Kim TJ: Expression of insulin-like growth factor 1 receptor (IGF-1R) predicts poor responses to epidermal growth factor receptor (EGFR) tyrosine kinase inhibitors in non-small cell lung cancer patients harboring activating EGFR mutations. Lung Cancer 87: 311-317, 2015.

46. Ma Y, Cheng Q, Ren Z, Xu L, Zhao Y, Sun J, Hu S and Xiao W: Induction of IGF-1R expression by EGR-1 facilitates the growth of prostate cancer cells. Cancer Lett 317: 150-156, 2012.

47. Gryko M, Kisluk J, Cepowicz D, Zińczuk J, Kamocki Z, Guzińska-Ustymowicz K, Pryczynicz A, Czyżewska J, Kemona A and Kędra B: Expression of insulin-like growth factor receptor type 1 correlate with lymphatic metastases in human gastric cancer. Pol J Pathol 65: 135-140, 2014

48. Shan HB, Zhang R, Li Y, Xu GL, Luo GY, Gao XY and Yang HL: Expression of IGF-1R in colorectal polyps and its role in colorectal carcinogenesis. Technol Cancer Res Treat 10: 381-389, 2011.

49. Xie QX, Lin XC, Zhang MF, Han CX and Guo YH: Expression of IGF-I and IGF-IR in bladder cancer. Ai Zheng 23: 707-709, 2004 (In Chinese).

50. Werner H and LeRoith D: The role of the insulin-like growth factor system in human cancer. Adv Cancer Res 68: 183-223, 1996.

51. Pollak M: The insulin and insulin-like growth factor receptor family in neoplasia: An update. Nat Rev Cancer 12: 159-169, 2012.

52. King H, Aleksic T, Haluska P and Macaulay VM: Can we unlock the potential of IGF-1R inhibition in cancer therapy? Cancer Treat Rev 40: 1096-1105, 2014.

53. Pavelić J, Radaković B and Pavelić K: Insulin-like growth factor 2 and its receptors (IGF $1 \mathrm{R}$ and IGF 2R/mannose 6-phosphate) in endometrial adenocarcinoma. Gynecol Oncol 105: 727-735, 2007. 